\title{
A Korean Girl with Campomelic Dysplasia caused by a Novel Nonsense Mutation within the SOX9 Gene
}

\author{
Jung Min Ko* ${ }^{1 *}$ J-Hun Hah², Suk-Wha Kim³, Tae-Joon $\mathrm{Cho}^{4}$, Gu-Hwan Kim ${ }^{5}$ and Han-Wook Yoo ${ }^{5}$
}

'Department of Pediatrics, ${ }^{2}$ Department of Otolaryngology, ${ }^{3}$ Department of Plastic Surgery, ${ }^{4}$ Department of Orthopedic Surgery, Seoul National University College of Medicine, Seoul, Korea

${ }^{5}$ Medical Genetics Center, Asan Medical Center, Seoul, Korea

Campomelic dysplasia (CMD) is a rare, often lethal, genetic disorder characterized by multiple congenital anomalies and abnormal development of the reproductive organs in males. Mutations in the SOX9 gene are known to cause CMD. We present a Korean CMD girl with a normal 46,XX karyotype and a female reproductive organ phenotype. She was born at $2.35 \mathrm{~kg}$ at 38 weeks of gestation and showed characteristic phenotypes, including cleft palate, micrognathia, hypertelorism, flat nasal bridge, congenital bowing of limbs, hypoplastic scapulae, deformed pelvis, and 11 pairs of ribs. She also had an atrioseptal defect of the heart and marked laryngotracheomalacia requiring tracheostomy and tracheopexy. SOX9 mutation analysis revealed the presence of a novel nonsense mutation, p.Gln369*, and the patient was genetically confirmed to have CMD. Although she showed marked failure to thrive and neurodevelopmental delay, she is now 40 months of age and is the only surviving patient with CMD in Korea.

Key words: Campomelic dysplasia, Laryngotracheomalacia, Cleft palate, Growth retardation, SOX9

\section{Introduction}

Campomelic dysplasia (CMD, MIM\#114290) is a rare autosomal dominant disorder that affects the development of multiple organ systems, particularly the skeletal and reproductive systems. Clinical features are characterized by congenital bowing and angulation of long bones, hypoplastic scapulae, deformed pelvis and spine, and a reduced number of ribs. Craniofacial anomalies, including cleft palate, micrognathia, and hypertelorism are also frequently associated with CMD." Approximately $75 \%$ of $46, X Y$ patients with CMD show ambiguous or complete female genitalia. ${ }^{2)} \mathrm{CMD}$ is often life-threatening during the newborn period, and respiratory distress due to laryngotracheomalacia contributes to neonatal death in these patients. Therefore, only a few patients with CMD survive past infancy. Survivors beyond infancy may also have scoliosis, short stature, and hearing loss with age."

CMD is caused by haploinsufficiency of the $50 \times 9$ gene at 17q24. The SOX9 protein is widely expressed as a transcription factor in many different tissues and organs during embryonic development and has also been suggested to play critical roles in the initiation and maintenance of chondrocyte differentiation and in male sex differentiation along with SRY., ${ }^{3,4)}$ Only one report of a genetically-confirmed CMD case in Korea is available. ${ }^{5}$

Received: 01 Nov 2012, Revised: 17 Dec 2012, Accepted: 18 Dec 2012, Published: 31 Dec 2012

${ }^{*}$ Corresponding author: Jung Min Ko, M.D.

Department of Pediatrics, Seoul National University College of Medicine, Pediatric Clinical Neuroscience Center, Seoul National University Children's Hospital, 101 Daehak-ro, Jongno-gu, Seoul 110-769, Korea

Tel: +82-2-2072-3570, Fax: +82-2-743-3455, E-mail: jmko@snu.ac.kr

(c) This is an open-access article distributed under the terms of the Creative Commons Attribution Non-Commercial License (http://creativecommons.org/licenses/by-nc/3.0/) which permits unrestricted non-commercial use, distribution, and reproduction in any medium, provided the original work is properly cited.

(c) Copyright 2012 by the Korean Society of Medical Genetics

www.e-kjgm.org 
Herein, we present a Korean girl with CMD resulting from a novel SOX9 mutation who had a 46,XX karyotype and manifested typical CMD clinical features.

\section{Case Report}

A 15-month-old Korean girl was referred to the Seoul National University Children's Hospital for surgical treatment of the airway and heart lesions leading to ventilator weaning failure. She was the first baby in the family, and the parents were healthy and nonconsanguineous. The patient was delivered by cesarean section at a regional hospital. Her birth weight was $2.35 \mathrm{~kg}\left(<3^{\text {rd }}\right.$ percentile $)$ at the 38 weeks of gestation. Bilateral shortening of all four limbs was suspected on prenatal ultrasonography. Immediate resuscitation by intubation was required for respiratory distress justafter birth.

At the initial examination after birth, relative macrocephaly, a small thoracic cage, short limbs with anterior femoral bowing, bilateral pretibial skin dimples, and bilateral club feet were identified (Fig. 1). She also displayed facial dysmorphism with hypertelorism, a depressed nasal bridge, low set ears, micrognathia, and a cleft in the soft palate. She had marked laryngotracheomalacia, and weaning from mechanical ventilation failed recurrently. Tracheostomy was performed at the age of 4 months, but intermittent ventilator care was required.

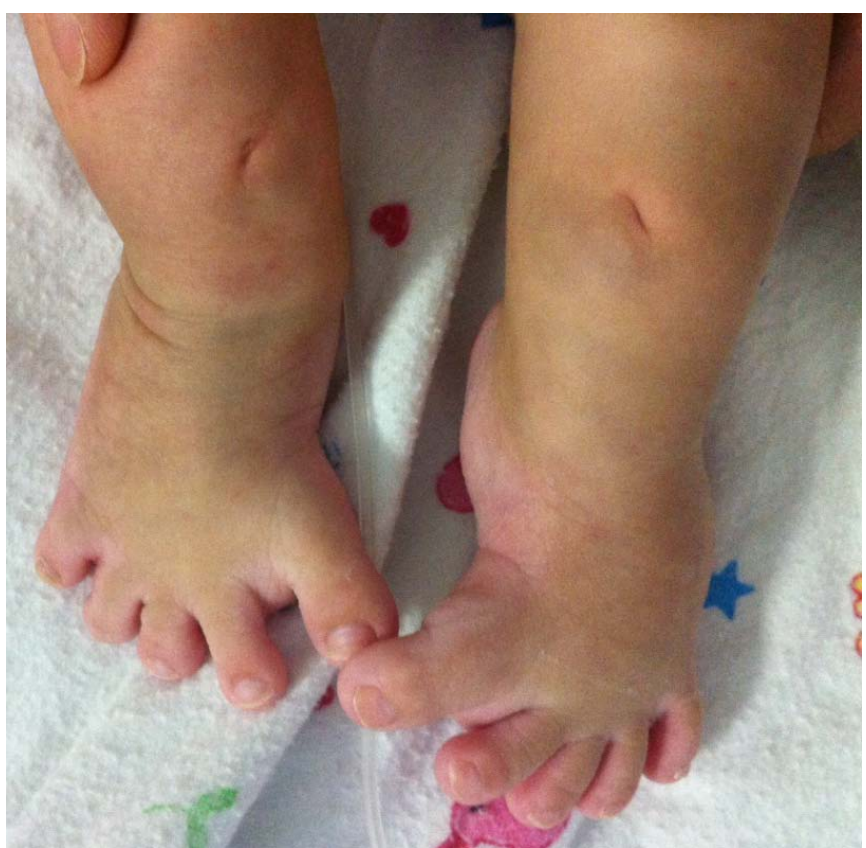

Fig. 1. Photograph of the patient's legs and feet shows bilateral lipoatrophy on anterior tibial skin, brachydactyly of the toes, and bilateral club feet.
At the age of 15 months, the patient's weight was $6.7 \mathrm{~kg}\left(<3^{\text {rd }}\right.$ percentile) and her length was $58 \mathrm{~cm}\left(<3^{\text {rd }}\right.$ percentile). She also required gavage tube feeding because her micrognathia, gastroesophageal reflux, and cleft palate caused feeding difficulties. A ventilated bronchoscopic examination showed dynamic narrowing of the lower trachea and the left main bronchus. Echocardiography showed a secundum atrioseptal defect without other malformations. Thus, tracheopexy and patch closure of the atrioseptal defect were performed. Mechanical ventilation was discontinued after the operation, and lifethreatening respiratory obstructive episodes resolved gradually with age, although her weight gain was consistently poor.

Skeletal radiographs showed cervical spine kyphosis, bilateral hypoplastic scapulae, bilateral hip dislocations, bilateral talipes equinovarus, bilateral shortening of tibiae and femora, anterior bowing of both tibiae, bilateral narrowing of the iliac wings, and 11 pairs of the ribs (Fig. 2). No intra-abdominal anomalies were observed on an ultrasonographic examination. Brain magnetic resonance imaging showed mild ventriculomegaly with brain atrophy and small subependimal nodular lesions in bilateral frontal horns suggesting white matter injury. Brainstem auditory evoked potentials were normal. The peripheral blood karyotype was 46,XX with normal female external genitalia.

CMD was suspected based on medical history and the physical examination findings. Analysis of the SOX9 gene was performed as a molecular genetic confirmation of CMD. The patient's genomic DNA was isolated from peripheral blood after obtaining informed consent from the legal representative. All three exons and the intronic flanking regions of the SOX9 gene were amplified by polymerase chain reaction using specific primers. Subsequently, DNA sequencing reactions were performed, and a novel nonsense mutation in exon 3, c.1105C >T (p.Gln369*), was detected (Fig. 3).

At 40 months of age, her weight and height were $7.0 \mathrm{~kg}$ $\left(<3^{\text {rd }}\right.$ percentile) and $61.1 \mathrm{~cm}\left(<3^{\text {rd }}\right.$ percentile), respectively.

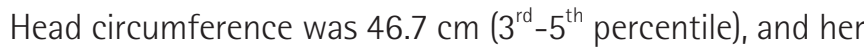
development was severely and globally delayed, as she could not sit with support or speak. A gastrostomy was scheduled, and repair of the cleft palate will be considered after catch-up growth in weight.

\section{Discussion}

CMD is a rare, often lethal, genetic disorder characterized by multiple congenital anomalies and abnormal development of 


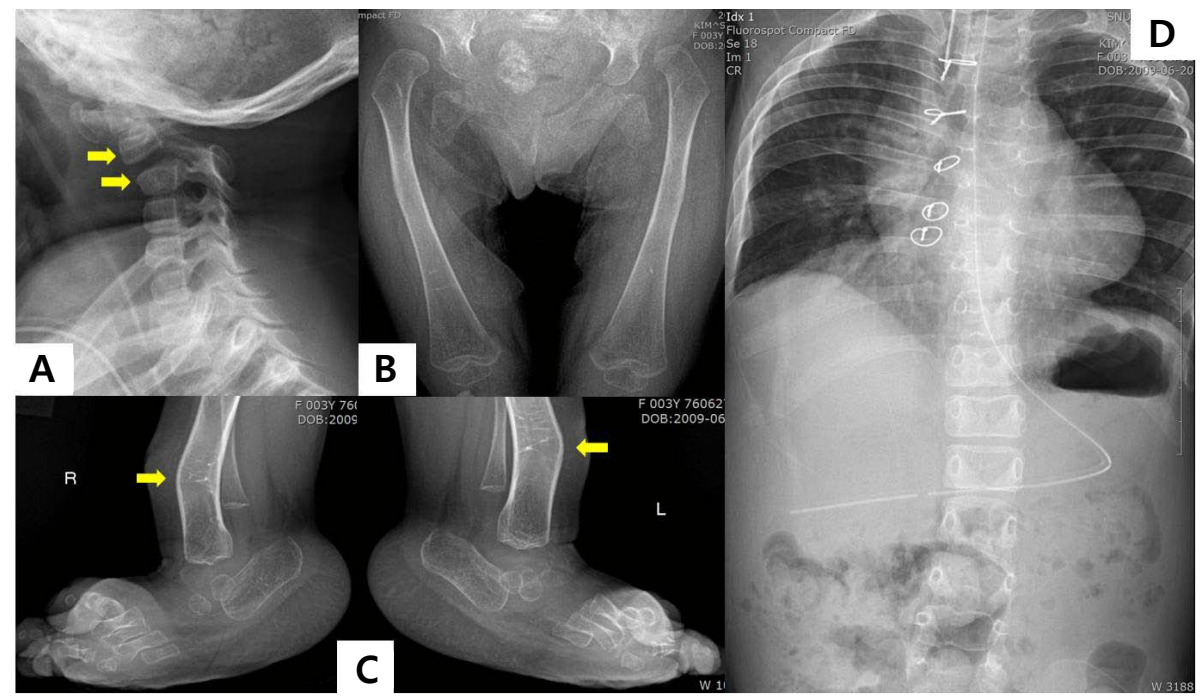

Fig. 2. Simple radiographs show anterior angulation of the C2-3 vertebrae (A), bilateral dislocation of the femoral heads (B), bilateral metatarsal varus deformity of the feet $(C)$, and anterior bowing of the tibiae, 11 pairs of the ribs, bilateral hypoplastic scapulae, scoliosis (D).

Normal $3 C G C C C C C A C A G C A G C C G G C G G C A C C$

Patient
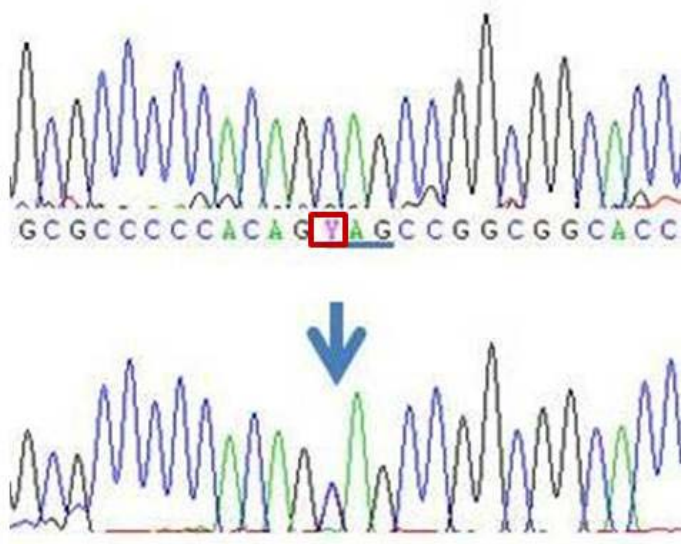

Fig. 3. Partial sequences of the $S O X 9$ gene show a heterozygous $\mathrm{C}>\mathrm{T}$ mutation at nucleotide 1105 of exon 3 , leading to a premature stop at codon 369 .

the reproductive organs in males. This condition affects the bones and cartilage throughout the body, causing significantly short limbs, bowed legs, distinctive facial features, and a narrow thorax. Death often results during the neonatal period because of respiratory problems associated with laryngotracheomalacia and a narrow thorax. Survivors beyond the first year after birth show improved quality of life, although mental retardation and progressive kyphoscoliosis are common complications."

The diagnosis of CMD is based on the presence of typical clinical features. Some of the skeletal anomalies are more obvious on radiological examination. Genetic testing of the SOX9 gene can lead to a confirmatory diagnosis of CMD. The SOX9 gene is the only CMD causal gene to date. However, more than 80 mutations in SOX9 have been reported worldwide.

The SOX9 protein is expressed throughout chondrogenesis and actsas a key regulator at multiplesteps of cartilage differentiation. ${ }^{6)}$ It is also expressed in the genital ridge of both genders, becoming up-regulated in the developing testes and down-regulated in the developing ovaries, consistent with an important role in male sex determination. ${ }^{7,8)}$ A previous in vivo study using transgenic mice showed direct evidence that ectopic expression of SOX9 causes testes development instead of ovaries in XX mice. ${ }^{9)}$ Furthermore, SOX9 binds to the promoters or enhancers of several chondrocyte and testis differentiation genes such as the collagen genes ${ }^{10,11)}$ and the testicular anti-mullerian hormone gene. ${ }^{12)}$

Reported SOX9 mutations in CMD are located across the entire gene and include missense, nonsense, frameshift, splice site mutations, and gross deletions. A nonsense mutation leads to truncation of the SOX9 protein that misses part or all of the transactivation domain at the C-terminus, suggesting that impairment of gonadal and skeletal development results from a failure of target gene activation. ${ }^{13)}$ Our patient carried a novel nonsense mutation, c.1105C $>T$ (p.Gln369*). This mutation is located in the proline, glutamine, and alanine-rich domain (PQA) but the function of the PQA is unknown. However, c.1105C>T leads to premature termination of $\mathrm{SOX}$ protein synthesis at codon 369, and the important transactivation domain (codons 402-509) is totally missed and can cause typical skeletal manifestations of CMD such as in our patient. Our patient was karyotyped as 46, XX and sex reversal can only be associated with males with the $46, X Y$ karyotype. The internal and external genitalia of our patient 
showed completely normal female structures. Besides intragenic mutations in SOX9, CMD has also been associated with complex chromosomal rearrangements involving $17 q$, such as reciprocal translocations, inversions, or deletions. ${ }^{14,15)}$ Although many SOX9 mutations have been reported, there has been no distinct genotype- phenotype correlation concerning mutation type or location and severity of the disease and sex reversal in male patients. $^{3,4)}$

Here, we report a girl with CMD resulting from a novel SOX9 mutation who showed a typical clinical phenotype. Although this syndrome is quite rare and often lethal, early diagnosis and management of associated complications may prevent sudden deterioration of clinical condition and improve patient quality of life. Only three cases of CMD have been reported in Korea. ${ }^{5}$ 16, 17) However, none of the cases survived to 4 months after birth, and only one case was molecular genetically confirmed as CMD. ${ }^{5}$ Although our patient showed severe failure to thrive and neurodevelopmental delay, our patient is the only surviving and the longest living case in Korea.

\section{Acknowledgements}

This study was supported by grant no. 2012R1A1A3001588 from the Korean Ministry of Education, Science and Technology.

\section{References}

1. Mansour S, Hall CM, Pembrey ME, Young ID. A clinical and genetic study of campomelic dysplasia. J Med Genet 1995;32:415-20.

2. Cameron FJ, Sinclair AH. Mutations in SRY and SOX9: testis-determining genes. Hum Mutat 1997;9:388-95.

3. Foster JW, Dominguez-Steglich MA, Guioli S, Kwok C, Weller PA, Stevanovic $\mathrm{M}$, et al. Campomelic dysplasia and autosomal sex reversal caused by mutations in an SRY-related gene. Nature 1994;372:525-30.

4. Wagner T, Wirth J, Meyer J, Zabel B, Held M, Zimmer J, et al. Autosomal sex reversal and campomelic dysplasia are caused by mutations in and around the SRY-related gene SOX9. Cell 1994;79:1111-20.

5. Kim HY, Yoon $\mathrm{CH}$, Kim GH, Yoo HW, Lee BS, Kim KS, et al. A case of campomelic dysplasia without sex reversal. J Korean Med Sci 2011;
$26: 143-5$

6. Akiyama H, Chaboissier MC, Martin JF, Schedl A, de Crombrugghe B. The transcription factor $50 X 9$ has essential roles in successive steps of the chondrocyte differentiation pathway and is required for expression of Sox5 and Sox6. Genes Dev 2002;16:2813-28.

7. Kent J, Wheatley SC, Andrews JE, Sinclair AH, Koopman P. A malespecific role for SOX9 in vertebrate sex determination. Development 1996:122:2813-22.

8. Morais da Silva S, Hacker A, Harley V, Goodfellow P, Swain A, LovellBadge R. SOX9 expression during gonadal development implies a conserved role for the gene in testis differentiation in mammals and birds. Nat Genet 1996;14:62-8.

9. Vidal VP, Chaboissier MC, de Rooij DG, Schedl A. SOX9 induces testis development in XX transgenic mice. Nat Genet 2001;28:216-7.

10. Lefebvre V, Huang W, Harley VR, Goodfellow PN, de Crombrugghe B. SOX9 is a potent activator of the chondrocyte-specific enhancer of the pro alpha1(II) collagen gene. Mol Cell Biol 1997;17:2336-46.

11. Bridgewater LC, Lefebvre V, de Crombrugghe B. Chondrocyte-specific enhancer elements in the Col11a2 gene resemble the Col2a1 tissuespecific enhancer. J Biol Chem 1998;273:14998-5006.

12. De Santa Barbara P, Bonneaud N, Boizet B, Desclozeaux M, Moniot B,

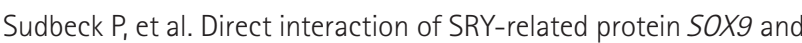
steroidogenic factor 1 regulates transcription of the human antiMullerian hormone gene. Mol Cell Biol 1998;18:6653-65.

13. Sudbeck P, Schmitz ML, Baeuerle PA, Scherer G. Sex reversal by loss of the C-terminal transactivation domain of human SOX9. Nat Genet 1996:13:230-2

14. Pfeifer D, Kist R, Dewar K, Devon K, Lander ES, Birren B, et al. Campomelic dysplasia translocation breakpoints are scattered over $1 \mathrm{Mb}$ proximal to SOX9: evidence for an extended control region. Am J Hum Genet 1999;65:111-24.

15. Pop R, Conz C, Lindenberg KS, Blesson S, Schmalenberger B, Briault $\mathrm{S}$, et al. Screening of the $1 \mathrm{Mb}$ SOX9 5 ' control region by array $\mathrm{CGH}$ identifies a large deletion in a case of campomelic dysplasia with $X Y$ sex reversal. J Med Genet 2004;41:e47.

16. Kim SK, Kim HC, Shin SJ, Lee MW, Lee YM, Cho JH, et al. A case of fetal skeletal anomaly of Campomelic syndrome. Korean J Obstet Gynecol 2000:43:311-4.

17. Chung CO, Bae HY, Kim DR, Park YH, Chung HS. A case of multiple congenital anomaly. Korean J Obstet Gynecol 1992;35:1407-13. 